autonomy has dawned as the dominant ethos in healthcare, markedly nullifying the previous paternalistic model. As a result of this radical swing of the pendulum, emphasis is placed on shared decision-making, and a greater responsibility is given to the patient in the management of their health. The importance of communication is being stressed more and more at undergraduate training, and different approaches to consultations are being taken by professionals to establish this. The implementation of guidelines to accredit this change in standard was formalised in the NHS Plan at the turn of the millennium: 'letters between clinicians about an individual patient's care will be copied to the patient as of right. ${ }^{1}$

It was hoped that this change would come into effect by 2004, and as a result of the protocol, hospitals around the UK have set copying letters to patients as part of their guidelines. Previous literature seems to have proven that letter sharing is beneficial for patients; in 2003 The Department of Health funded 12 Pilot Projects, which showed that copying letters to patients improves communication between health care professionals. ${ }^{2}$ A review of previous literature in 2006 found that patients generally find copies of letters beneficial, and tend to be more satisfied with their consultation, whereas healthcare professionals are generally less keen to copy letters. ${ }^{3}$

A recent audit carried out in Barts and The Royal London NHS Trust found that $77 \%$ of patients wanted copies of their clinical letters. However, only 13\% of the clinicians actually took consent to copy letters, with the main reason being that they forget to. From sitting in on multiple consultations in various specialties, the results of this audit do not seem to be a far cry from the reality in many hospital clinics.

It is understandable that a change in previous habits can be difficult to maintain after the administration of a new system. With the ever evolving clinician-patient relationship, all health professionals must be adept at adjusting to the reforming surroundings. This, in a field which rests heavily upon the importance of good communication; between not only the multi-disciplinary team involved in the care of the patient, but also between the clinician-patient relationship itself.

$$
\begin{aligned}
& \text { O. Taha, I. } \\
& \text { Al-Hadad, } \\
& \text { C. Gallagher } \\
& \text { By email }
\end{aligned}
$$

1. Department of Health. The NHS plan: a plan for investment a plan for reform. London: Department of Health, 2007. Available from: http://www. dh.gov.uk/en/Publicationsandstatistics/Publications/PublicationsPolicyAndGuidance/Browsable/ DH_4112374

2. Harris C, Boaden R. Copying letters to patients: summaries of 12 pilot project sites. Manchester: Health Organisations Research Centre, 2003. Available from: http://www.dh.gov.uk/prod_con sum_dh/groups/dh_digitalassets/@dh/@en/ documents/digitalasset/dh_4020449.pdf

3. Harris C, Boaden R. Copying letters to patients: the view of patients and health professionals. J Health Serv Res Policy 2006; 11: 133-140.

DOI: $10.1038 /$ sj.bdj.2011.296

\section{INSPIRED BY A TUG}

Sir, following an agonising couple of days, culminating in a visit to a dental hospital, I wrote a short humorous poem about a dental experience from the patient's perspective for my writing class and thought that I might share it with your readers too. Since my visit all has been well!

\section{Age 102 in miserableness}

Up through my head and down

through my jaw

Straight through my shoulder and into my core.

Drains concentration, addles my brain,

Sweating and swearing and

lost in the pain.

Head in my hands, roll on the floor,

Simply don't think I can

stand any more.

Begging and pleading to

just make it end

Needles and forceps,

reluctant best friends

Crunching and grinding,

then gone with a tug

First time I've given a dentist a hug.

J. C. Barker

By email

DOI: 10.1038/sj.bdj.2011.297 